\title{
RSP Revisitada A estatística e a administração: notas de aula do curso de organização do trabalho
}

Nelson Spinola Teixeira

Antigo Secretário da Viação e Obras Públicas no Estado da Baía

Escrito em 1940, período em que a Revista do Serviço Público tinha a maior parte de seu conteúdo dedicado a comunicações internas - em uma seção denominada vida administrativa -, ao direito administrativo, o artigo de Nelson Spinola Teixeira trata do uso da estatística no estudo científico de maneira geral e sua aplicação na administração. $O$ autor busca estabelecer uma distinção entre o que ele chama de técnica do método experimental e a técnica do método estatístico. Em seguida, o texto busca diferenciar o que são fenômenos individuais, coletivos e de multidão. Após tecer diversas considerações de caráter epistemológico, o autor finaliza indicando que aplicação esses conceitos científicos podem ter para a administração. Ao final do texto, ao criticar a ideia de que um "fato global, o fato total, fato geral seja apenas uma soma dos fatos individuais" e afirmar que "ambos, entretanto, têm natureza diversa", o autor enuncia um dos argumentos evocados atualmente em discussões sobre o uso da perspectiva multinível em estudos organizacionais. A estatística constitue um método de estudo que, dia a dia, aumenta seu campo de aplicação. 
Esta expansão do campo de aplicação da estatística é motivada em parte pela tendência atual de estudo da natureza segundo os termos de suas quantidades. Precisamos conhecer as coisas sob a forma das medidas de suas grandezas.

Ora, o processo de se medir os fatos de natureza coletiva e, principalmente, os fatos que não comportam um estudo experimental, se fundamenta no método estatístico, que se poderia definir como sendo o método de observação científica, em contraposição ao método de experimentação.

Quando - para o estudo científico de um determinado fenômeno, fato ou acontecimento - tivermos o poder de controlar todas as fôrças ou influências que agem sôbre êsse mesmo fenômeno, fato ou acontecimento de tal maneira a podermos repetir êsse fenômeno, empregamos, para o seu estudo o método experimental, utilizado em quasi toda a física e quasi toda a química.

Quando, entretanto, as causas atuantes são tais de modo a não termos controle sôbre as mesmas, o fenômeno só poderá ser observado e nunca reeditado.

A todos os fenômenos, cuja realização podemos reeditar ou provocar, aplica-se o método experimental e aos fenômenos para cujas causas atuantes não possuímos elementos de controle, temos de aplicar o método estatístico, ou seja o método de observação.

Em que consistem as diferenças essenciais da técnica do método experimental e da técnica do método estatístico?

Podemos salientar uma diferença substancial, entre uma e outra técnica de estudo.

Antes de examinar essa diferença convém que sejam esclarecidas as diversas naturezas de causas que agem sôbre os fenômenos e o que se deve definir como sendo o estudo de um fato, um fenômeno ou um acontecimento.

Sôbre qualquer fato ou acontecimento agem tres fundamentais complexos diferentes de causas - causas permanentes e constantes; causas variaveis, mas com uma certa lei nessa variabilidade, isto é, causas cíclicas; e causas de todo irregulares e acidentais.

A ação dessas diferentes naturezas de causas pode se dar conjuntamente ou separadamente.

O estudo de um fenômeno não é mais do que a análise dos efeitos resultantes das causas permanentes. Estudar o fenômeno é saber, ou melhor, procurar saber os resultados das causas que agem permanentemente sôbre o mesmo. 0 experimentalista age da seguinte forma: podendo controlar os complexos de causas que têm ação sôbre o fenômeno, procura crear o ambiente ideal, mais ou menos perfeito, no qual sejam afastadas todas essas causas acidentais, todas essas causas 
variaveis e, examinando o fenômeno nestas condições favoraveis, leva a efeito o seu trabalho de pesquisa e observação. A técnica do seu método procura agir sôbre as causas para isolar as suas diferentes influências afim de melhor estudá-las.

Isso que é simples de enunciar, exige muitas vezes uma experiência de longos anos, pois um bom experimentalista não se forma rapidamente. Através de experimentações feitas metodicamente, conseguimos isolar os efeitos correspondentes a cada causa, obtendo o modo e a intensidade de como influe a temperatura, a densidade, ou a natureza dos reagentes em uma experimentação química, por exemplo.

O método experimental lança mão de uma técnica do controle e isolamento das causas, através das quais são estudados os efeitos dessas mesmas causas.

Quando e trata entretanto de fenômeno que não podemos reeditar, como os que ocorrem na natureza, o seu estudo não poderá ser feito com o emprêgo dessa técnica de controle das causas que estabelece ambientes propícios, senão ideais para o estudo do fenômeno. Tem-se que estudar o fenômeno tal como se apresenta, não sendo possível reeditá-lo, ou provocar a sua realização. Vejamos o exemplo do crescimento humano. Como cresce uma criança, dos quatro meses aos dois anos de idade? Não podemos reeditar o crescimento de uma criança.

Do mesmo modo que não podemos reeditar a aprendizagem humana. Uma pessoa que inicia seus estudos e aprende determinadas cousas, não poderá, nunca, repetir de novo essa aprendizagem, para efeito de análise ou estudo desta mesma aprendizagem.

Os fenômenos biológicos, via de regra, não podem ser reeditados.

O mesmo ocorre com fenômenos naturais - o curso dos astros - o curso das águas, o clima, etc.

Como devemos proceder em face dêsses fenômenos, para conseguir o isolamento das causas perturbadoras, afim de conhecer seus efeitos?

Nos fenômenos não reeditáveis, como isolar o efeito das causas acidentais para conseguir o efeito puro, das causas permanentes?

Temos de empregar um método que possua uma técnica de estudo diferente daquela técnica do método experimental. Essa técnica é a do método estatístico, mediante a qual fazemos não a observação do fenômeno dentro de condições, previamente estabelecidas, mas ao contrário fazemos repetidas observações. Repetindo certo número de observações, somando todos os resultados dessas operações e calculando a média, esta média da observação do fato é um resultado correspondente ao efeito das causas permanentes, pois as causas perturbadoras e acidentais se anulam com um grande número de observações. 
Aqui temos a lei central de Estatística: "A lei dos grandes números".

Nesse detalhe resume-se todo o fundamento da técnica do método estatístico.

$E^{\prime}$ o método de estudo baseado na observação repetida dos fenômenos, tal como êles se apresentam.

Vejamos um caso concreto e singelo: - o crescimento de uma criança. Como encontrar o crescimento normal de uma criança, no Rio de Janeiro? O seu crescimento típico, um crescimento que seja a lei do crescimento da criança no Rio de Janeiro? Simplesmente fazendo um grande número de observações. Serão duas, tres, cinco mil crianças, nas quais observamos o crescimento. Com êsse número elevado de crianças, - ou mesmo de todas as crianças do Rio de Janeiro, - teremos todos os crescimentos. Somando, então, todos êsses crescimentos, e dividindo-os pelo número total de observações, acharemos um crescimento médio, que será a lei do crescimento da criança no Rio de Janeiro, isto é, o seu crescimento normal, ou seja o crescimento resultante da ação das causas permanentes e constantes.

Encontramos neste exemplo os dois complexos de causas - causas constantes ao crescimento de todas as crianças, e causas acidentais, que variam de criança para criança, ligadas à natureza de seus pais, ao seu estado de saúde, à sua alimentação, etc. São causas acidentais, peculiares a cada criança, e diferentes de criança para criança.

Assim, ao procurarmos a lei do crescimento da criança, procurávamos o efeito das causas constantes e permanentes, e essa lei de crescimento da criança é obtida pela repetição das observações.

O conhecimento do mundo só pode ser feito através dêsses dois métodos: o método experimental das ciências experimentais e o método estatístico de estudo das demais ciências; o método de estudo dos fenômenos que podem ser reeditados pelo homem e o método de estudo dos fenômenos que não podem ser realizados pelo homem.

Com êste ponto de vista alargamos imensamente o campo da aplicação do método estatístico.

Em verdade, tudo aquilo que, para ser estudado, estiver sujeito a repetições ou sucessivas observações, está subordinado ao estudo pelo método estatístico. Essas questões de estatística ganham, hoje, tal amplitude que é comum afirmarse que tudo quanto, em economia, não fôr conhecido em termos estatísticos, não representa um conhecimento científico.

Esclarecida essa diferenciação, convem examinarmos as categorias de fenômenos que existem na natureza.

Todos os fatos e todos os conhecimentos do mundo podem ser classificados dentro das seguintes categorias: a categoria dos fenômenos individuais; dos fenômenos coletivos; e dos fenômenos de multidão. 
Que são fenômenos individuais, coletivos e de multidão?

Os fenômenos cujos efeitos resultantes das causas permanentes se evidenciam com pequeno número de observações são chamados fenômenos individuais. O fenômeno coletivo é o fenômeno no qual os efeitos resultantes das causas permanentes só se evidenciam com um grande número de observações. Em outros termos, poderíamos dizer que o fenômeno individual é aquele onde há uma predominância das causas permanentes, de tal modo que a evidenciação da ação a causas permanentes se dá com um pequeno número de observações.

No fenômeno coletivo a ação de causas acidentais de certo modo possue influência idêntica à ação das causas permanentes. O efeito do complexo de causas permanentes e constantes que existe ao lado das causas acidentais e perturbadoras só se evidencia com grande número de observações, que anula os efeitos resultantes das causas perturbadoras.

Os fenômenos individuais são, geralmente, os fenômenos do campo experimental.

Os fenômenos coletivos ou de multidão são mais comuns entre os que são estudados pelo método estatístico, baseado no grande número de observações.

Os fenômenos de multidão são aqueles sobre os quais só agem causas acidentais. Já expliquei que estudar um fenômeno é apurar os efeitos das suas causas permanentes. Como estudar êsses fenômenos nos quais só agem causas acidentais?

A mortalidade, por exemplo, é o caso típico de um fenômeno de multidão; do mesmo modo a temperatura, a pressão dos gases.

A morte individual é, sem dúvida, um efeito resultante de causas acidentais. Ninguém pode, estudando êsse fenômeno, determinar o dia em que um determinado indivíduo vai morrer. $\mathrm{O}$ ato individual de morrer é inteiramente imprevisível com antecedência.

Não existem complexos de causas permanentes que nos levem a estudar a mortalidade de modo a determinar com precisão qual seja o ciclo vital individual de uma determinada pessoa.

Mas si estudarmos uma multidão de duas mil ou mesmo de vinte mil pessoas, poderemos obter nesta multidão uma lei absolutamente regular da mortalidade. Isso pode parecer fantástico, mas é tanto mais verdadeiro quanto conhecemos a prosperidade das companhias de seguros, que orientam os seus lucros baseados nessa lei. Ha, assim, uma lei para o grupo, para o todo e cujo conhecimento podemos obter independente do conhecimento da lei de partícula, isto é, do elemento ou do indivíduo componente dêsse todo ou dêsse grupo. 
No caso do crescimento da criança o problema é diverso. No crescimento da criança, temos as causas permanentes e as causas acidentais; e quando inferimos a média de todas as crianças, obtemos o crescimento típico, normal, relativo a um indivíduo, a uma criança. No fenômeno da mortalidade, temos de enunciar a lei para o grupo ou para a multidão, que não tem qualquer significação para o indivíduo. Independente do conhecimento da lei individual, podemos conhecer a lei do grupo dêsses indivíduos.

Hoje em dia, a ciência está chegando à conclusão de que um grande número de fenômenos anteriormente estudados sôbre outros pontos de vista, constituem fenômenos de multidão para os quais as leis têm o carater de leis estatísticas relativas ao modo de ser do grupo, tal como a lei da mortalidade, que, sendo real para uma multidão de pessoas, não tem nenhum significado para cada uma das pessoas individualmente consideradas.

Todo o mundo físico é constituído de fenômenos de multidão. Não nos é possivel conhecer a lei individual do procedimento de um de terminado eletron, foton e ion; podemos unicamente estabelecer as leis estatísticas dos grupos de fotons, de ions e de eletrons. A lei do elemento e da partícula escapa ao conhecimento humano.

Que aplicação poderiam ter para a administração êstes conceitos científicos ?

A administração pública, si bem examinarmos, deve ser estudada como sendo um fenômeno de multidão. Não nos interessa conhecer os casos pessoais ou individuais. Precisamos ter as regularidades estatísticas obtidas pelo estudo sistemático dos processos e dos resultados da administração.

O conhecimento dessas regras independe do conhecimento dos procedimentos individuais, devendo o problema ser examinado em seus aspectos globais, cujas regras podem ser conhecidas, independentemente do estudo do caso individual.

$E^{\prime}$ comum os administradores pensarem que administrar significa solucionar casos pessoais, supondo que o fato global, o fato total, fato geral, seja apenas uma soma dos fatos individuais.

Ambos, entretanto, têm natureza diversa. 